\title{
Minireview
}

\section{ALL-I/MLLI, a homologue of Drosophila TRITHORAX, modifies chromatin and is directly involved in infant acute leukaemia}

\author{
E Canaani; ${ }^{*, 1}$, T Nakamura², T Rozovskaia', ST Smith², T Mori' ${ }^{2}$ CM Croce ${ }^{2}$ and A Mazo ${ }^{*, 2}$ \\ 'Department of Molecular Cell Biology, Weizmann Institute of Science, Rehovot, Israel 76 100; ${ }^{2}$ Kimmel Cancer Center, Thomas Jefferson University, \\ Philadelphia, PA 19107, USA
}

Rearrangements of the ALL-I/MLLI gene underlie the majority of infant acute leukaemias, as well as of therapy-related leukaemias developing in cancer patients treated with inhibitors of topoisomerase II, such as VPI6 and doxorubicin. The rearrangements fuse ALL-I to any of > 50 partner genes or to itself. Here, we describe the unique features of ALL-I-associated leukaemias, and recent progress in understanding molecular mechanisms involved in the activity of the ALL-I protein and of its Drosophila homologue TRITHORAX.

British Journal of Cancer (2004) 90,756-760. doi:I0.1038/sj.bjc.660I639 www.bjcancer.com

(c) 2004 Cancer Research UK

Keywords: acute lymphoblastic and myelogeneous leukaemia; mouse models; chromatin; epigenetic marking

\section{ACUTE LEUKAEMIAS ASSOCIATED WITH ALL- 1 REARRANGEMENTS}

Chromosome band 11q23 is involved in reciprocal chromosome translocations in $5-10 \%$ of children and adults with acute lymphoblastic leukaemia (ALL) or acute myelogeneous leukaemia (AML). Nearly all these rearrangements affect the $A L L-1$ gene, also termed MLL1, HRX and HTRX, located at 11q23. The translocations occur within an $8.3 \mathrm{~kb}$ breakpoint cluster region of the gene and result in the replacement of $A L L$-1-coding sequence 3' to the breakpoint by the coding sequence of the translocation partner (Gu et al, 1992; Tkachuk et al, 1992). In a second and less frequent type of rearrangement, $A L L-1$ undergoes partial tandem duplication (self-fusion), resulting in the production of a larger protein (Schichman et al, 1995). The most common ALL-1 translocations are $t(4 ; 11), t(9 ; 11), t(11 ; 19), t(6 ; 11)$ and $t(10 ; 11)$, accounting for $40,27,12,5$ and $5 \%$ of cases, respectively. However, the total number of different loci participating in $A L L-1$ translocations is amazingly high and has already exceeded 50 (Huret et al, 2001).

There is an association between particular chromosomal translocations involving $A L L-1$ and subtypes of leukaemias. Thus, $\mathrm{t}(4 ; 11)$ nearly always occurs in $\operatorname{ALL}, \mathrm{t}(9 ; 11)$ is mostly associated with AML, as are $\mathrm{t}(11 ; 19)(\mathrm{q} 23 ; \mathrm{p} 13.1), \mathrm{t}(6 ; 11), \mathrm{t}(10 ; 11)$ and the partial duplications. $t(11 ; 19)(q 23 ; p 13.3)$ occurs in both AML and ALL. ALL1-associated ALLs are characterised as $\mathrm{CD} 10^{-}, \mathrm{CD} 19^{+}$ and by B-cell precursor phenotype (pro B), with a high frequency of myeloid-associated (CD15 and/or CD65) antigen expression. Hence, they are also designated biphenotypic or mixed-lineage leukaemia. The AMLs are usually of the myelomonocytic (FABM4) or monoblastic (FAB-M5) morphological subtypes and sometimes express cell-surface lymphoid markers. The prognosis

*Correspondence: E Canaani; E-mail: eli_canaani@weizmann.ac.il or A Mazo; E-mail: A_Mazo@lac.jci.tju.edu

Received 12 August 2003; revised 14 December 2003; accepted I5 December 2003 of patients with 11q23 abnormalities is dismal. Age is an important prognostic factor. Thus, less than $25 \%$ of infants $(<1$ year) and adults older than 40 or 50 years, with $t(4 ; 11)$ or $t(9 ; 11)$, are cured. Patients of intermediate age, in particular 2-9 or 1-14 years old, have significantly better prognosis (Johansson et al, 1998; Swansbury et al, 1998; Pui et al, 2002).

The hallmark of ALL1-associated leukaemias is their epidemiology (reviewed in Greaves, 1999; Biondi et al, 2000). They predominate infant acute leukaemia $(80 \%$ of ALL and $65 \%$ of AML), and account for the majority of therapy-related (secondary) leukaemias developing in $5-15 \%$ of primary cancer patients who had received intensive chemotherapy, including epipodophyllotoxins (VP16) and anthracyclines (doxorubicin) (Pui and Relling, 2000). These drugs are inhibitors of topoisomerase II, and act by stabilising double-strand DNA breaks generated by this enzyme. In both infant and secondary leukaemias, the latency period is remarkably brief. In infants, $A L L-1$ rearrangements can be already detected in utero and the average age at diagnosis is 6 months, and in secondary leukaemias, latency averages around 18-30 months (reviewed in Greaves, 1999; Pui and Relling, 2000). The very brief time between the initiating event and clinical disease, in conjunction with the high rate of concordance in identical twins with infant leukaemia, points to the effectiveness of ALL-1 fusion proteins in driving the initial clone into frank leukaemia. Based on the findings from therapy-related leukaemia, it was hypothesised (Ross et al, 1994) that transplacental exposure of the foetus to natural substances that inhibit topoisomerase II (such as flavonoids in foods and drinks) might play a role in infant leukaemia. Such exposure will induce accumulation of DNA's free ends from within the breakpoint cluster region of $A L L-1$, and this would eventually result in 11q23 translocations. The results of recent biochemical experiments (Strick et al, 2000) are consistent with this hypothesis. A structural feature shared by many topoisomerase II inhibitors, including anticancer drugs, is the quinone moiety. The metabolism of quinones is controlled by the enzyme NQO1 that converts toxic benzoquinones to 
hydroxyquinones. A polymorphism in nucleotide 609 of the enzyme substitutes a proline into serine and consequently inactivates the enzyme. Comparison of paediatric leukaemias with and without ALL-1 rearrangement indicated significant bias in the former for NQO1 genotypes conferring low or no enzymatic activity (Wiemels et al, 1999; Smith et al, 2002), suggesting that inactivating NQO1 polymorphism increases the risk for ALL-1associated leukaemias.

\section{MOUSE MODELS OF ALL-1 LEUKAEMOGENESIS}

Two methodologies have been used to generate mouse models of $A L L-1$ leukaemogenesis. Knockin of the partner gene AF9 into the $A L L-1$ locus by homologous recombination resulted in animals that developed AML at approximately 6 months (Dobson et al, 1999). Transmission of the transgene in the germ line and its expression during embryogenesis resulted in viable progeny. This, together with the observation that mice carrying a single null allele of ALL-1 were not predisposed to AML (Corral et al, 1996), rules out a model of leukaemogenesis due to haploinsufficiency (passive loss of function). Rather, an extensive series of investigations applying retro viral transduction into cultured haematopoietic progenitor cells, followed by transplantation into mice, have established that $A L L-1$ fusion genes act as dominant alleles and the disease is due to $A L L-1$ gain of function. Structure-function analysis of several ALL-1 fusion proteins showed that particular elements within the partner proteins, such as transcription effector domains and protein-protein interaction motifs, are critical for the leukaemogenic activity (reviewed in Ayton and Cleary, 2001). The presence of dimerisation domains in some of the partner proteins, such as AF6, AF10, AF17, AF1p, GAS7 and AF3p21 suggested that self-association might underlie the role of the partner proteins with such motifs in the leukaemogenicity of ALL1 fusion proteins. The most compelling experimental evidence for this is that homodimerisation of ALL-1 by synthetic dimerisation modules mimics many of the features of ALL-1 fusion proteins (Dobson et al, 2000; So et al, 2003b, Martin et al, 2003). Also, disruption of the dimerisation motifs in some partner proteins eliminated pathogenicity. Although self-dimerisation appears to play a key role in leukaemogenesis associated with partner proteins containing a dimerisation motif, the most common fusions - ALL-1/AF4, ALL-1/AF9 and ALL-1/ENL - do not dimerise.

Both the knockin and retroviral transduction approaches turned out to be biased towards myeloid leukaemia. However, very recent studies with virally transduced ALL1-ENL (Zeisig et al, 2003) and ALL1-GAS7 (So et al, 2003a) showed transformation of biphenotypic lymphoid/myeloid cells and induction of biphenotypic leukaemia. So et al serially plated the transduced bone marrows in methylcellulose and found that the fusion protein conferred long-term growth capacity to multipotential progenitors. The progenitors spontaneously differentiated into biphenotypic and myeloid progenitors during culturing in vitro. Moreover, mice injected with the transduced serially-plated progenitors developed either biphenotypic leukaemia, or AML or ALL. On the basis of these experiments, it was proposed that ALL-1 fusion proteins enhance the self-renewal potential of multipotent progenitors that retain an ability to differentiate into downstream progeny. The latter are more susceptible to differentiation blocking by ALL-1 fusion proteins, or are prone to secondary mutations required for full malignant transformation.

\section{GENE EXPRESSION PROFILES OF ALL-1 LEUKAEMIAS}

DNA microarrays technology has been recently applied to construct expression profiles of ALLs and/or AMLs with ALL-1 rearrangements (Rozovskaia et al, 2001, 2003; Armstrong et al, 2002; Yeoh et al, 2002). Both ALL-1-associated ALLs and AMLs have distinct expression patterns that distinguish them from other types of ALL and AML, respectively. The distinction is more robust for ALL, probably reflecting the unusual clinical and biological features and the biphenotypic trait of the disease, not shared by other classes of ALL. In one study (Rozovskaia et al, 2003), genes whose expression pattern separated ALLs with $t(4 ; 11)$ from other ALLs were further subdivided, enabling the identification of two subfamilies of $t(4 ; 11)$ tumours. In that study, a substantial number of the genes, which were found to correlate in their expression with the $t(4 ; 11)$ genotype, had been previously associated with cancer, apoptosis or growth control. These included overexpressed oncogenes (such as HOX A9, HOX A10, MEIS1, LMO2 and MYC), overexpressed genes involved in protection from apoptosis and in survival, underexpressed proapoptotic genes, overexpressed genes involved in drug resistance and underexpressed tumour suppressors and growth inhibitors such as FHIT and DAPK1.

Determination of which of the genes pointed out in the DNA microarrays analyses plays a direct role in pathogenesis might come from experiments with mice. One approach will be to alter the expression (e.g. by interference RNA) of a suspected gene in cell lines with 11q23 translocations, and examine whether the capacity of the cell lines to induce leukaemia in mice is lost. The second approach will be to transduce the fusion genes into mice null for genes suspected of playing an essential role in $A L L-1$ pathogenesis, and examine the effect on leukaemia development. Such an experiment has been recently reported for HOX A9 and HOX A7 (Ayton and Cleary, 2003). These two genes were found required for in vitro myeloid immortalisation by the MLL/ENL fusion protein transduced by a retroviral vector into bone marrow cells. Further, HOX A9 was found to be indispensable for ALL-1dependent leukaemogenesis in vivo. Applying a complementary approach, Kumar et al (2004) bred mice to obtain animals transgenic for $M L L-A F 9$ and null for $H O X A 9$ and examined leukaemia development. Surprisingly, the absence of HOX A9 did not affect the incidence and latency of leukaemia, although the malignant cells displayed a more immature myeloid phenotype. The authors suggest that several HOX genes might have to be inactivated to impair leukaemogenicity. The reasons for the contrasting conclusion obtained by the two approaches are currently not known.

\section{BIOLOGICAL AND BIOCHEMICAL ACTIVITY OF ALL-1 AND ITS DROSOPHILA HOMOLOGUE TRITHORAX (TRX)}

$A L L-1$ and TRX are members of the evolutionary conserved gene family termed as the Trx group (TrxG) that are positive regulators of the homeotic gene complex (HOX) during development, and whose activity is opposed by the repressive activity of the Polycomb group (PcG). The TrxG and PcG proteins are not required for initiation of $H O X$ genes activity, but act to maintain transcriptional states through later stages of development (reviewed in Brock and van Lohuizen, 2001; Simon and Tamkun, 2002). $A L L-1$ also acts at the stage of maintenance (Yu et al, 1998). Since considerably more genetic and biological information is available about $T R X$, in comparison to $A L L-1$, here we will emphasise studies of the former. Approximately 20 genes have been characterised as members of the fly TrxG; however, this number is rapidly growing based on genetic and molecular criteria (Gildea et al, 2000; Faucheux et al, 2003). Further, it has became apparent that the target genes of the TrxG are not limited to HOX genes (Kuzin et al, 1994; Maurange and Paro, 2002; Beltran et al, 2003). In this context, we have recently demonstrated (Smith et al, 2004) that following heat induction, the TRX complex is quickly recruited to several heat-shock genes on salivary polytene chromosomes, where it is required to maintain a high level of 
already initiated transcription. Such a role is similar to the role of TRX in HOX gene expression.

Much effort was devoted to in vivo analysis of the properties of TrxG and PcG response elements (TRE and PRE, respectively) at target loci in Drosophila. The emerging picture of the best studied target, the regulatory region of the Drosophila Bithorax complex $B X-C$ gene $U b x$, suggests that although TREs and PREs are intermingled within a $1.5 \mathrm{~kb}$ region $b x d$, they may represent separable regulatory elements (Tillib et al, 1999). It is still not clear whether the TrxG and PcG proteins occupy their respective responsive elements at all time, or only when the target gene is active or repressed, respectively. Evidence that these proteins may occupy their binding sites depending on the status of gene expression came recently from analysis of Drosophila larval fat body (Marchetti et al, 2003). BX-C genes are repressed in the anterior region of the fat body, but are active in the mid-posterior part. In parallel, the PC protein (but not TRX) was detected at the cytological site of bithorax on polytene chromosomes from the anterior part of the fat body, while a strong signal of TRX (but not of PC) was detected on chromosomes from the mid-posterior fat body.

The mechanism by which TRX and ALL-1 reach their target loci is not known. The absence of sequence-specific DNA-binding protein among components of the TRX and ALL-1 complexes (see later) emphasises this quandary. Several recent studies (Bender and Fitzgerald, 2002; Hogga and Karch, 2002; Rank et al, 2002) showed that ectopic or induced transcription through regulatory elements of the Bithorax complex switches the elements from silenced to activated states. On the basis of this, it was proposed that passage of the RNA polymerase II complex through a regulatory element displaces the repressive PcG complex, set there by default, and enables recruitment of the TRX complex that imprints epigenetic marks instructing transcription of the adjacent HOX gene.

Chromatin immunoprecipitation (ChIP) experiments previously identified TRX both on TREs and on promoters within the Bithorax gene complex (Orlando et al, 1998). The ChIP methodology was recently applied to ALL-1 (Nakamura et al, 2002; Milne et al, 2002) and the protein was found bound at the promoters of $\mathrm{HOX} A 9$ and $\mathrm{HOX} C 8$ in cultured cells expressing these genes (homologues of Drosophila TREs and PREs have not been identified yet in mammals). Elimination of ALL-1, by applying interference RNA methodology, blocked transcription of HOX A9. Both studies showed that ALL-1 is a histone methyltransferase that methylates lysine 4 of histone H3. The enzymatic activity is conferred by the C-terminal SET domain. The presence of ALL-1 on the promoters of the two HOX genes is linked to H3-Lys4 methylation as well as to acetylation of histones $\mathrm{H} 3$ and $\mathrm{H} 4$ at the promoter. Several other TrxG, PcG, and other chromatin - associated proteins containing SET domains - were recently shown to methylate histones at specific residues (reviewed in Orlando, 2003). Such marking of histones (as are acetylation, phosphorylation and ubiquitination of specific histone residues) conveys heritable transcription patterns (expression or silencing) in an epigenetic manner.

The molecular mechanisms by which TRX and ALL-1 act was further elucidated by the identification and characterisation of stable protein complexes associated with the two proteins. TRX is a component of the TAC1 complex that includes the histone acetyltransferase (HAT) dCBP, and a SET - binding factor, SBF1 (Petruk et al, 2001). The recruitment of TAC1 components to the HSP70 locus following heat induction results in enhanced expression of the gene and correlates with acetylation and methylation of histones (Smith et al, 2004). The ALL-1 complex (Nakamura et al, 2002) completely varies from that of TRX. It contains at least 29 proteins. The majority of the latter are components of seven subcomplexes involved in transcription preinitiation, nucleosome remodelling, histone deacetylation, histone methylation or RNA processing. The purified ALL-1 complex methylates, acetylates, deacetylates and remodels nucleosomes and is bound at the promoter of the target gene HOX A9. It appears that a major role of ALL-1 is to assemble this large supercomplex of enzymatic activities. In summary, the recent biochemical experiments indicate that TRX and ALL-1 recruit to target genes a host of enzymatic activities, mostly involved in epigenetic marking. The way in which these marks are inherited to progeny cells (memorized) is not known (they have to survive DNA replication, during which the histones are thought to be stripped off the DNA), but it has been speculated (Turner, 2000; Richards and Elgin, 2002) that the modified histones stay at or near the replication fork and are incorporated into the daughter DNA strands.

\section{UNRESOLVED ISSUES AND FUTURE DIRECTIONS}

While considerable progress was made in identification of the biochemical activities of the ALL-1 and TRX protein complexes, the mechanism by which these complexes are recruited to specific sequences (genes) is completely unknown. The recent reports that transcription of regulatory regions induces heritable transcriptional activation of the Drosophila $B X-C$ genes raises the possibility that such a mechanism is involved in the recruitment of TRX and ALL-1 complexes. Another outstanding issue is the identification of genes, other than HOX, that are regulated by ALL1 and TRX. The demonstration that the mammalian PcG protein BMI-1 regulates the important cell cycle locus INK4a/ARF (Jacobs et al, 1999) suggests that looking for additional ALL-1/TRX targets (e.g. by conditional elimination or activation of the two proteins, followed by DNA microarray analysis) might be rewarding. Further, the process by which the ALL-1-mediated histone H3Lys4 methylation induces chromatin alteration (presumably decondensation) and gene expression, and the precise roles of the transcriptional subcomplexes within ALL-1 supercomplex, have yet to be determined. A new line of investigation is likely to originate from the recent remarkable finding that the PHD finger motif of the ING2 protein binds phosphoinositides, and that this interaction regulates the biological activity of the latter (Gozani et al, 2003). The presence of four PHD finger motifs in both ALL-1 and TRX points to a potential central mechanism by which these proteins are regulated. Finally, the reason why ALL-1 (and presumably TRX) is proteolytically cleaved by an evolutionary conserved enzyme into two polypeptides, which are held together, is not known (Nakamura et al, 2002; Yokoyama et al, 2002; Hsieh et al, 2003).

Mouse models have recently identified the type of precursor cell transformed by ALL-1 fusion proteins, and DNA microarrays analyses focused attention on genes that might play a direct role in leukaemogenesis. Identification of such genes is clearly a focal point for understanding the disease in molecular terms and for future therapeutic intervention. However, other central questions remain. First, do all ALL-1 fusions, including self-fusions, trigger a single pathway leading to disease? Why are most fusions associated with specific leukaemia subtype (e.g. ALL1-AF4 with ALL, ALL1AF6 with AML)? Second, since the fusion proteins lack the SET domain with its histone H3-Lys4 methylation activity, how do they retain transcriptional activation capacity? Do they target all genes regulated by normal ALL-1? Do they compete with normal ALL-1 on the same targets? Do they block transcription of some loci? Also, the absence of the PHD fingers in ALL-1 fusion proteins should relieve them from potential regulation by phosphoinositides; whether this is an important aspect of the leukaemogenic activity of these proteins has yet to be determined. A third issue is whether ALL-1 fusions confer resistance to apoptosis. ALL-1associated leukaemias are notorious for their poor prognosis with chemotherapy, and exhibit drug resistance. Since it is now believed 
that the cytotoxic action of most chemotherapeutic drugs is through activation of apoptotic pathways, drug resistance of ALL-1 leukaemias might be due to disruption of apoptotic processes. Such disruptions appear to be crucial for the development of many tumours (reviewed in Johnstone et al, 2002). Still, very little has been reported about this issue with regard to ALL-1 leukaemias. In one study (Kersey et al, 1998), ALLs with $t(4 ; 11)$ were compared to similar tumours without $\mathrm{t}(4 ; 11)$ and found to be dramatically more resistant to serum deprivation stress. A recent investigation (Wiederschain et al, 2003) showed nuclear colocalisation of the fusion protein ALL1-ELL with p53, and loss of p53-mediated apoptosis. Whether this phenomenon is unique to that particular fusion protein or is it of a more general nature is presently not known.

\section{ACKNOWLEDGEMENTS}

We apologise to our colleagues whose work was not cited, due to space limitations. Work in the authors' laboratories was supported by NCI Grant CA50507 and by grants from the Israeli Academy of Science, the Israeli Cancer Research Fund and US-Israel BSF.

\section{REFERENCES}

Armstrong SA, Staunton JE, Silverman LB, Pieters R, den Boer ML, Minden MD, Sallan SE, Lander ES, Golub TR, Korsmeyer SJ (2002) MLL translocations specify a distinct gene expression profile that distinguishes a unique leukemia. Nat Genet 30: 41-47

Ayton PM, Cleary ML (2001) Molecular mechanisms of leukemogenesis mediated by MLL fusion proteins. Oncogene 20: $5695-5707$

Ayton PM, Cleary ML (2003) Transformation of myeloid progenitors by MLL oncoproteins is dependent on Hoxa7 and Hoxa9. Genes Dev 17: $2298-2307$

Beltran S, Blanco E, Serras F, Perez-Villamil B, Guigo R, ArtavanisTsakonas S, Corominas M (2003) Transcriptional network controlled by the trithorax-group gene ash2 in Drosophila melanogaster. Proc Natl Acad Sci USA 100: $3293-3298$

Bender W, Fitzgerald DP (2002) Transcription activates repressed domains in the Drosophila bithorax complex. Development 129: 4923-4930

Biondi A, Cimino G, Pieters R, Pui C-H (2000) Biological and therapeutic aspects of infant leukemia. Blood 96: 24-33

Brock HW, van Lohuizen M (2001) The polycomb group - no longer an exclusive club? Curr Opin Genet Dev 11: 175-181

Corral J, Lavenir I, Impey H, Warren AJ, Forster A, Larson TA, Bell S, McKenzie AN, King G, Rabbitts TH (1996) An MLL-AF9 fusion gene made by homologous recombination causes acute leukemia in chimeric mice: a method to create fusion oncogenes. Cell 85: 853-861

Dobson CL, Warren AJ, Pannel R, Forster A, Lavenir I, Corral J, Smith AJ, Rabbitts TH (1999) The MLL-AF9 gene fusion in mice controls myeloproliferation and specifies acute myeloid leukemogenesis. EMBO J 18: $3564-3574$

Dobson CL, Warren AJ, Pannell R, Forster A, Rabbitts TH (2000) Tumorigenesis in mice with a fusion of the leukaemia oncogene Mll and the bacterial lacZ gene. EMBO J 19: $843-851$

Faucheux M, Roignant JY, Netter S, Charollais J, Antoniewski C, Theodore L (2003) Batman interacts with polycomb and trithorax group genes and encodes a BTB/POZ protein that is included in a complex containing GAGA factor. Mol Cell Biol 23: 1181-1195

Gildea JJ, Lopez R, Shearn A (2000) A screen for new trithorax group genes identified little imaginal discs, the Drosophila melanogaster homologue of human retinoblastoma binding protein 2. Genetics 156: 645-663

Gozani O, Karuman P, Jones DR, Ivanov D, Cha J, Lugovskoy AA, Baird CL, Zhu H, Field SJ, Lessnick SL, Villasenor J, Mehrotra B, Chen J, Rao VR, Brugge JS, Ferguson CG, Payrastre B, Myszka DG, Cantley LC, Wagner G, Divecha N, Prestwich GD, Yuan J (2003) The PHD finger of the chromatin-associated protein ING2 functions as a nuclear phosphoinositide receptor. Cell 114: $99-111$

Greaves M (1999) Molecular genetics, natural history and the demise of childhood leukaemia. Eur J Cancer 35: 1941-1953

Gu Y, Nakamura T, Alder H, Prasad R, Canaani O, Cimino G, Croce CM, Canaani E (1992) The $t(4 ; 11)$ chromosome translocation of human acute leukemia fuses the $A L L-1$ gene, related to Drosophila trithorax, to the AF4 gene. Cell 71: $701-708$

Hogga I, Karch F (2002) Transcription through the iab-7 cis-regulatory domain of the bithorax complex interferes with Polycomb mediated silencing. Development 129: 4915-4922

Hsieh JJ, Cheng EH, Korsmeyer SJ (2003) Taspasel: a threonine aspartase required for cleavage of MLL and proper HOX gene expression. Cell 115: $293-303$

Huret JL, Dessen P, Bernheim A (2001) An atlas of chromosomes in hematological malignancies. Example: $11 \mathrm{q} 23$ and MLL partners. Leukemia 15: 987-989
Jacobs JJL, Kieboom K, Marino S, DePinho RA, van Lohuizen M (1999) The oncogene and Polycomb group gene bmi-1 regulates cell proliferation and senescence through the INK4a locus. Nature 397: 164-168

Johansson B, Moorman AV, Haas OA, Watmore AE, Cheung KL, Swanton S, Secker-Walker LM (1998) Hemotologic malignancies with $t(4 ; 11)$ (q21;q23): a cytogenetic, morphologic, immunophenotypic and clinical study of 183 cases. Leukemia 12: 779-787

Johnstone RW, Ruefli AA, Lowe SW (2002) Apoptosis: a link between cancer genetics and chemotherapy. Cell 108: $153-164$

Kersey JH, Wang D, Oberto M (1998) Resistance of t(4;11)(MLL-AF4 fusion gene) leukemias to stress-induced cell death: possible mechanism for extensive extramedullary accumulation of cells and poor prognosis. Leukemia 12: 1561 - 1564

Kumar AR, Hudson WA, Chen W, Nishiuchi R, Yao Q, Kersey JH (2004) Hoxa9 influences the phenotype but not the incidence of Mll-AF9 fusion gene leukemia. Blood, inpress, Epub 2003, Nov 13

Kuzin B, Tillib S, Sedkov Y, Mizrokhi L, Mazo A (1994) The Drosophila trithorax gene encodes a chromosomal protein and directly regulates the region-specific homeotic gene forkhead. Genes Dev 8: 2478-2490

Marchetti M, Fanti L, Berloco M, Pimpinelli S (2003) Differential expression of the Drosophila BX-C in polytene chromosomes in cells of larval fat bodies: a cytological approach to identifying in vivo targets of the homeotic Ubx, Abd-A and Abd-B proteins. Development 130: 3683-3689

Martin ME, Milne TA, Bloyer S, Galoian K, Shen W, Gibbs D, Brock HW, Slany R, Hess JL (2003) Dimerization of MLL fusion proteins immortalizes hematopoietic cells. Cancer Cell 4: 197-207

Maurange C, Paro R (2002) A cellular memory module conveys epigenetic inheritance of hedgehog expression during Drosophila wing imaginal disc development. Genes Dev 16: 2672-2683

Milne TA, Briggs SD, Brock HW, Martin ME, Gibbs D, Allis CD, Hess JL (2002) MLL targets SET domain methyltransferase activity to HOX gene promoters. Mol Cell 10: 1107-1117

Nakamura T, Mori T, Tada S, Krajewski W, Rozovskaia T, Wassel R, Dubois G, Mazo A, Croce CM, Canaani E (2002) ALL-1 is a histone methyltransferase that assembles a supercomplex of proteins involved in transcriptional regulation. Mol Cell 10: 1119-1128

Orlando V (2003) Polycomb, epigenomes and control of cell identity. Cell 112: $599-606$

Orlando V, Jane EP, Chinwalla V, Harte PJ, Paro R (1998) Binding of Trithorax and Polycomb proteins to the bithorax complex: dynamic changes during early Drosophila embryogenesis. EMBO J 17: $5141-5150$

Petruk S, Sedkov Y, Smith S, Tillib S, Kraevski V, Nakamura T, Canaani E, Croce CM, Mazo A (2001) Trithorax and dCBP acting in a complex to maintain expression of homeotic gene. Science 294: 1331-1334

Pui C-H, Gaynon PS, Boyett JM, Chessells JM, Baruchel A, Kamps W, Silverman LB, Biondi A, Harms DD, Vilmer E, Schrappe M, Camitta B (2002) Outcome of treatment in childhood acute lymphoblastic leukemia with rearrangements of the $11 \mathrm{q} 23$ chromosomal region. Lancet 359: $1909-1915$

Pui C-H, Relling MV (2000) Topoisomerase II inhibitor-related acute myeloid leukemia. Br J Haematol 109: 13-23

Rank G, Prestel M, Paro R (2002) Transcription through intergenic chromosomal memory elements of the Drosophila bithorax complex correlates with an epigenetic switch. Mol Cell Biol 22: 8026-8034

Richards EJ, Elgin SCR (2002) Epigenetic codes for heterochromatin formation and silencing. Rounding up the usual suspects. Cell 108: 489-500

Ross JA, Potter JD, Robison LL (1994) Infant leukemia, topoisomerase II inhibitors, and the MLL gene. J Natl Cancer Inst 86: 1678-1680 
Rozovskaia T, Feinstein E, Mor O, Foa R, Blechman J, Nakamura T, Croce CM, Cimino G, Canaani E (2001) Upregulation of Meis1 and HOXA9 in acute lymphocytic leukemias with the $(4 ; 11)$ abnormality. Oncogene 20: $874-878$

Rozovskaia T, Ravid-Amir O, Tillib S, Getz G, Feinstein E, Agrawal H, Nagler A, Rappaport EF, Issaeva I, Matsuo Y, Kees UR, Lapidot T, Lo Coco F, Foa R, Mazo A, Nakamura T, Croce CM, Cimino G, Domany E, Canaani E (2003) Expression profiles of acute lymphoblastic and myeloblastic leukemias with ALL-1 rearrangements. Proc Natl Acad Sci USA 100: $7853-7858$

Schichman SA, Canaani E, Croce CM (1995) Self fusion of the ALL-1 gene. A new genetic mechanism for acute leukemia. JAMA 273: 571-576

Simon JA, Tamkun JW (2002) Programming off and on states in chromatin: mechanisms of polycomb and trithorax group complexes. Curr Opin Genet Dev 12: $210-218$

Smith MT, Wang Y, Skibola CF, Slater DJ, Lo Nigro L, Nowell PC, Lange BJ, Felix CA (2002) Low $\mathrm{NAD}(\mathrm{P}) \mathrm{H}$ : quinone oxidoreductase activity is associated with increased risk of leukemia with MLL translocations in infants and children. Blood 100: $4590-4593$

Smith ST, Petruk S, Sedkov Y, Cho E, Tillib S, Canaani E, Mazo A (2004) Modulation of heat shock gene expression by TAC1 chromatin modifying complex. Nat Cell Biol, in press

So CW, Karsunky H, Passegué E, Cozzio A, Weissman IL, Cleary ML (2003a) MLL-GAS7 transforms multipotent hematopoietic progenitors and induces mixed lineage leukemias in mice. Cancer Cell 3: $161-171$

So CW, Lin M, Ayton PM, Chen EH, Cleary ML (2003b) Dimerization contributes to oncogenic activation of MLL chimeras in acute leukemias. Cancer Cell 4: $99-110$

Strick R, Strissel PL, Borgers S, Smith SL, Rowley JD (2000) Dietary bioflavonoids induce cleavage in the MLL gene and may contribute to infant leukemia. Proc Natl Acad Sci USA 97: 4790-4795

Swansbury GJ, Slater R, Bain BJ, Moorman AV, Secker-Walker LM (1998) Hematological malignancies with $\mathrm{t}(9 ; 11)(\mathrm{p} 21-22 ; \mathrm{q} 23)$ : a laboratory and clinical study of 125 cases. Leukemia 12: $792-800$
Tillib S, Petruk S, Sedkov Y, Kuzin A, Fujioka M, Goto T, Mazo A (1999) Trithorax- and Polycomb-group response elements within an ultrabithorax transcription maintenance unit consist of closely situated but separable sequences. Mol Cell Biol 19: 5189-5202

Tkachuk DC, Kohler S, Cleary ML (1992) Involvement of a homologue of Drosophila trithorax by 11q23 chromosome translocations in acute leukemias. Cell 71: $691-700$

Turner BM (2000) Histone acetylation and an epigenetic code. BioEssays 22: $836-845$

Wiederschain D, Kawai H, Gu J, Shilatifard A, Yuan Z-M (2003) Molecular basis of $\mathrm{p} 53$ functional inactivation by the leukemic protein MLL-ELL. Mol Cell Biol 23: $4230-4246$

Wiemels JL, Pagnamenta A, Taylor GM, Eden OB, Alexander FE, Greaves MF (1999) A lack of a functional $\mathrm{NAD}(\mathrm{P}) \mathrm{H}$ : quinone oxidoreductase allele is selectively associated with pediatric leukemias that have MLL fusions. Cancer Res 59: 4095-4099

Yeoh E-J, Ross ME, Shurtleff SA, Williams WK, Patel D, Mahfouz R, Behm FG, Raimondi SC, Relling MV, Patel A, Cheng C, Campana D, Wilkins D, Zhou X, Li J, Liu H, Pui C-H, Evans WE, Naeve C, Wong L, Downing JR (2002) Classification, subtype discovery, and prediction of outcome in pediatric acute lymphoblastic leukemia by gene expression profiling. Cancer Cell 1: 133-143

Yokoyama A, Kitabayashi I, Ayton PM, Cleary ML, Ohki M (2002) Leukemia proto-oncoprotein MLL is proteolytically processed into 2 fragments with opposite transcriptional properties. Blood 100: $3710-$ 3718

Yu BD, Hanson RD, Hess JL, Horning SE, Korsmeyer SJ (1998) MLL, a mammalian trithorax-group gene, functions as a transcriptional maintenance factor in morphogenesis. Proc Natl Acad Sci USA 95: $10632-$ 10636

Zeisig BB, Garcia-Cuellar MP, Winkler TH, Slany RK (2003) The oncoprotein MLL-ENL disturbs hematopoietic lineage determination and transforms a biphenotypic lymphoid/myeloid cell. Oncogene 22: $1629-1637$ 